\title{
A EXPERIÊNCIA DE UMA PRÁTICA PREVENTIVA COM ADOLESCENTES EM SITUAÇÃO DE RISCO
}

\author{
The experience of a preventive practice with adolescents at risk. \\ La experiencia de una práctica de prevención con adolescentes en riesgo
}

Paula Xavier Gums Mendes ${ }^{1}$

Jussara Gue Martini²

Telma Elisa Carraro ${ }^{3}$

Jonas Salomão Spricigo ${ }^{4}$

\section{RESUMO}

A prática assistencial aqui relatada teve como objetivo desenvolver com os adolescentes participantes oficinas de prevenção ao uso de drogas. Trata-se de uma prática assistencial que parte do conhecimento, da análise da realidade dos adolescentes, do desenvolvimento de estratégias e da síntese do conhecimento construído. As oficinas foram realizadas no período de dezembro de 2003 a fevereiro de 2004, com a participação de 10 adolescentes residentes na periferia de Florianópolis e considerados em situação de vulnerabilidade e risco social. Percebeu-se que eles, dentro do seu contexto social, vivem uma incongruência com a sua vida e infringem regras sociais, impossibilitando sua realização pessoal.

Palavras-chave: Adolescente. Transtornos Relacionados ao Uso de Substâncias. Educação.

\begin{abstract}
The practice care reported here aimed to develop the adolescents participating workshops to prevent the use of drugs. This is a practical assistance to the knowledge, analysis of the reality of adolescents, the development of strategies and the synthesis of knowledge built. The workshops were conducted from December 2003 to February 2004 with the participation of 10 adolescents living in the suburbs of Florianopolis and considered in a situation of vulnerability and social risk. They were perceived in its social context have a mismatch with their lives and break social rules, their realization impossible.
\end{abstract}

Keywords: Adolescents. Substance-Related Disorders. Education

\section{Resumen}

La práctica de atención que se describe aquí tiene por objetivo desarrollar con los adolescentes que participaron de los talleres para prevenir el consumo de drogas. Se trata de una asistencia práctica a los conocimientos, el análisis de la realidad de los adolescentes, el desarrollo de estrategias y la síntesis de los conocimientos construidos. Los talleres se llevaron a cabo entre diciembre de 2003 y febrero de 2004 con la participación de 10 adolescentes que viven en los suburbios de Florianópolis y son considerados en situación de vulnerabilidad y riesgo social. Se percibió que en sus contextos sociales tenía un desajuste con sus vidas y ellos rompían las normas sociales, lo que imposibilitaba su realización personal.

Palabras-clave: Adolescente. Trastornos relacionados con substancias. Educación.

\footnotetext{
'Psicóloga, Mestranda do Curso de Pós-Graduação em Enfermagem - UFSC (Universidade Federal de Santa Catarina).Florianópolis-SC-Brasil. E-mail: paulapsicologia@hotmail.com ,2Professora da UFSC, Enfermeira e Doutora do Curso de Pós-Graduação em Enfermagem - UFSC (Universidade Federal de Santa Catarina).Florianópolis-SC-Brasil. E-mail: jussarague@gmail.com ,3 Professora da UFSC, Enfermeira e Doutora do Curso de Pós-Graduação em Enfermagem UFSC (Universidade Federal de Santa Catarina).Florianópolis-SC-Brasil. E-mail: telmacarraro@nfr.ufsc.br ,4 Professor da UFSC, Enfermeiro e Doutor do Curso de Pós-Graduação em Enfermagem - UFSC (Universidade Federal de Santa Catarina).Florianópolis-SC-Brasil. E-mail: jonas@ccs.ufsc.br
} 


\section{INTRODUÇÃO}

0 presente relato de experiência trata das atividades desenvolvidas para a conclusão da Disciplina NFR Desenvolvimento Prático do Processo de Cuidar na Promoção da Saúde e Prevenção ao Uso indevido de Drogas, do currículo do Curso de Especialização Fenômeno das drogas: área da redução da demanda, do Departamento de Enfermagem da Universidade Federal de Santa Catarina. A disciplina acontece através do planejamento e desenvolvimento de uma prática assistencial, aplicando os conhecimentos do curso ao assistir e cuidar do adolescente (no caso desta experiência). A prática, com base no conhecimento e na análise da realidade dos adolescentes, visa ao desenvolvimento de estratégias de atenção e à síntese do conhecimento construído.

A prática assistencial foi realizada com jovens em situação de vulnerabilidade e risco social pertencentes a famílias com renda per capita de até meio salário mínimo, adolescentes que estão fora da escola e que cometeram atos infracionais, estando sob medida protetiva (artigo 101 do ECA ${ }^{(1)}$ ). Estes adolescentes fazem parte de um projeto intitulado Agente Jovem, um programa do Governo Federal executado pelas Prefeituras Municipais. Tem como fonte de financiamento recursos do Governo Federal para pagamento das bolsas-auxilio e capacitadores, possuindo parceria com a empresa White Martins no custeio de 25 adolescentes, e conta ainda com recursos da Prefeitura Municipal de Florianópolis para sua manutenção.

Esses jovens recebem uma bolsa (ajuda financeira) no valor de $\mathrm{R} \$ 65,00$ por mês, e a concessão dessa bolsa depende da frequência mínima de $75 \%$ das atividades pertinentes ao programa e das atividades das instituições de ensino nas quais os jovens estão inseridos. Os adolescentes recebem capacitações teórico-práticas, com duração de 12 meses, bem como atividades de cultura, esporte e lazer, e há a busca de talentos no grupo, 0 que tornando mais estimulante e atraente sua permanência no projeto.

0 termo de permanência do jovem no programa é de um ano. Em caso de extremo risco social, poderá o Conselho Tutelar ou o Conselho de Assistência Social validar a permanência do jovem por mais dois anos. Ao completar 18 anos, o adolescente é necessariamente desligado.

A equipe do projeto é composta pela coordenação, capacitadores, monitores, técnicos administrativos e grupo de apoio (Psicologia e Serviço Social). Como o projeto funciona durante um ano, a cada mês e à medida que os temas são trabalhados, mudam os capacitadores.

No caso desta prática, foi apresentado um projeto sobre o uso indevido de drogas para a coordenação do projeto, prevendo a realização de 10 oficinas envolvendo 10 adolescentes da periferia de Florianópolis, com idades entre 15 e 17 anos.

Para trabalhar com adolescentes é importante que 0 educador conheça seu contexto de vida, pois isto poderá ajudá- lo a compreender as transformações que se apresentam nesta fase da vida, gerando a insegurança que aparece, muitas vezes, sem que 0 adolescente perceba.

É importante que o educador entenda que o adolescente necessita e quer ajuda, para que possa alcançar um equilibrio psíquico tão importante na caminhada em direção à maturidade. Nesta fase, muitas vezes, o adolescente toma a decisão de experimentar o álcool ou outra droga, pois o período que atravessa se caracteriza pelo desafio às autoridades, às normas, às leis e às instituições em geral; pelo espírito de aventura, pela curiosidade, na busca de novas sensações e descober tas. Seu humor é quase sempre instável: da tristeza à euforia; da solidão à sociabilidade; age impulsivamente, não pensa nas consequências de seus atos, muitas vezes. Tem atitudes reivindicatórias, reclama por justiça social, muitas vezes de forma exacerbada. É capaz de passar da rebeldia à delinquência, caso não haja clareza e orientação quanto aos seus limites. Considerando as características acima, é fundamental orientá-lo para os riscos decorrentes da curiosidade de experimentar a droga. ${ }^{2}$

O uso indevido de drogas tem sido tratado, na atualidade, como questão de ordem internacional, objeto de mobilização organizada das nações em todo o mundo. Segundo dados publicados pela ONU, aproximadamente 208 milhões de pessoas, $4,8 \%$ da população adulta do mundo, usaram drogas ilícitas ao menos uma vez em 2007. Metade delas usou pelo menos uma vez ao mês, e, em média, cerca de 200 mil usuários morreram no ano passado em consequência do consumo de drogas. Os dependentes de drogas correspondem a $0,6 \%$ da população e somam 26 milhões. ${ }^{3}$.

Esta situação afeta a estabilidade das estruturas sociais, ameaça valores políticos, econômicos, humanos e culturais dos Estados e sociedades, contribuindo para o crescimento dos gastos com internação hospitalar e tratamento médico, para o aumento dos índices de acidentes, de violência urbana e de mortes prematuras, e, ainda, para a queda de produtividade dos trabalhadores. Geralmente começa com os adolescentes, afetando adultos, idosos, pessoas com ou sem instrução, profissionais especializados ou sem qualificação. As instituições tentam, por meio da política, da educação e da justiça, solucionar essa questão, mas os resultados têm se mostrado insuficientes para solucioná-la. A regulamentação do Sistema Nacional Antidrogas - SISNAD, estrutura sistêmica que tem a finalidade de organizar e integrar as forças nacionais públicas, privadas e não governamentais para o combate ao uso indevido e ao tráfico ilícito de drogas, pode ser apontada como um exemplo destes esforços. ${ }^{4,5}$

Observa-se que a problemática da droga não pode ser reduzida à adoção de medidas simples e isoladas, como as palestras, o reforço da segurança e da vigilância nas escolas. Sugere-se pensar em ações e estratégias de ação com efeitos de longo prazo, e que promovam o investimento no potencial 
dos jovens para que eles se tornem sujeitos de suas histórias, com condições objetivas e subjetivas para optar por outros caminhos que não o do consumo de drogas. ${ }^{6,7,8}$

A droga representa para a nossa sociedade um modismo, e o acesso a ela é muito fácil, além de ser "prazerosa" e muito difundida atualmente. A ampliação deste fenômeno, bem como seu caráter evolutivo, causa surpresas à sociedade, especialmente às famílias que reagem, ora com medo, ora com agressividade, à procura de um culpado que as liberte deste mal. Por isso, é necessário trabalhar com a prevenção, que é tudo aquilo que pode ser feito ou empreendido para impedir ou, pelo menos, reduzir o consumo de drogas.

A partir desta problemática, propõe-se a realização de oficinas educativas. A teoria escolhida para dar suporte ao trabalho foi a humanista. Segundo o autor da teoria, almeja-se que, no mundo moderno, se possa sensibilizar e incentivar os adolescentes a buscar a promoção da saúde, ou seja, impulsionando-os a favor do bom estado das funções orgânicas, físicas e mentais, e a criarem soluções próprias para os desafios. 0 objetivo principal da educação é proporcionar ao indivíduo condições favoráveis ao seu desenvolvimento enquanto sujeito histórico, isto é, enquanto um ser responsável pelos seus atos e com capacidade de empreender e de transformar a si mesmo. ${ }^{9}$

Por isso, houve a iniciativa e a mobilização para uma prática com adolescentes em situação de risco, sensibilizandoos para a prevenção ao uso das drogas, procurando orientálos, instruí-los a refletir sobre os seus estilos de vida.

\section{METOLOGIA-PRÁTICA ASSISTENCIAL}

A prática assistencial de enfermagem é uma disciplina do curso de especialização intitulado Fenômeno das drogas: área da redução da demanda, desenvolvido no período de 03/2003 a 05/2004. 0 objetivo da disciplina é estimular no educando o desenvolvimento das atitudes e habilidades para a assistência prestada aos indivíduos e grupos prioritários, no caso deste relato, um grupo de adolescentes.

A disciplina de prática assistencial, com 60 horas/ aula foi desenvolvida no período de 12/2003 a 03/2004, tendo por objetivo articular as ações de pesquisa a um projeto de intervenção, buscou aplicar em uma experiência prática os conhecimentos adquiridos na formação de especialista. A metodologia da disciplina inclui o planejamento, a intervenção e avaliação dos resultados da prática assistencial.

No caso aqui relatado, a prática assistencial consistiu de uma intervenção educativa junto a um grupo de adolescentes, cumprindo medidas socioeducativas. Inicialmente, identificaram-se o potencial de benefícios e riscos à saúde aos quais estavam expostos e suas necessidades de sobrevivência e de aperfeiçoamento para ser saudável. Com base no potencial de benefícios e de riscos à saúde identificados e na capacidade de resposta dos adolescentes, elaborou-se um plano de intervenção para atendimento dessas necessidades e desenvolveu-se a intervenção proposta; em seguida, procedeu-se à avaliação e reinterpretação das ações realizadas.

A partir da experiência com adolescentes com perfil de liberdade assistida, percebe-se a dificuldade de estimulá-los a refletir sobre as suas vidas. 0 objetivo foi propor exercícios que despertassem suas habilidades pessoais, suas aspirações e reflexões sobre seu estilo de vida, para provocar a mudança e auxiliá-los na compreensão de suas identidades. Outra meta foi mostrar a importância de compreender a responsabilidade do jovem diante das questões de saúde em relação às drogas, ampliando sua visão profissional, sua ambição, sua vivência na sociedade e na economia.

Para o desenvolvimento desta prática utilizou-se o Modelo de Cuidado de Carraro (1994), o qual consiste em cinco etapas, descritas a seguir: conhecendo-nos; reconhecendo a situação; desenvolvendo o trajeto e selecionando as estratégias; seguindo e agindo; e acompanhando a trajetória.

Desta forma, o primeiro passo da metodologia desta prática assistencial, qual seja conhecê-los, iniciou com 0 conhecimento dos adolescentes, por meio do nome, da idade, o que fazem, porque estão neste projeto, enfim um diagnóstico da situação do grupo de adolescentes inseridos na atividade. "[...] a obtenção dos dados descritivos é adquirida em contato direto com 0 ambiente e situação investigada. Sempre considerando como importantes todos os dados da realidade, busca-se conhecer os fenômenos sociais em sua especificidade e complexidade, sem deixar de levar em consideração o contexto no qual estão inseridos" 10:34.

0 segundo passo, reconhecendo a situação, buscou fazer uma análise da realidade vivida pelos adolescentes. Nesta análise utilizaram-se as dinâmicas de autoconhecimento: a dinâmica dos "crachás personalizados": o grupo deveria fazer os seus crachás. Desenvolveu-se sua criatividade a partir dessa atividade, além de permitir a observação da forma como expressam sua identidade. Neste crachá solicitou-se aos adolescentes que colocassem o nome, idade, figura que representa sua infância (seu passado), figura que representa sua adolescência (seu presente), figura que representa sua vida adulta (seu futuro). 0 objetivo desta dinâmica foi proporcionar ao jovem um ambiente de troca de experiências com os outros e observar a percepção que eles têm de si mesmos como pessoas.

Na segunda dinâmica utilizou-se a técnica da caixa surpresa, com o objetivo de refletir sobre o que a vida pode 
oferecer, a partir de nossas escolhas. 0 grupo em circulo recebeu uma caixa com vários embrulhos; à medida que a música ia tocando eles passavam o embrulho, quando a música parava, a pessoa que estava com o pacote retirava a parte externa do embrulho, e assim por diante. No final, a pessoa que ficava com o embrulho ganhava um pacote de balas, que depois era compartilhado com a turma. Mas no decorrer de toda a dinâmica, os adolescentes pensavam que era alguma coisa ruim, pois disse que o que tem dentro daquela caixa é algo que terão de usar na frente de todo mundo.

$\mathrm{Na}$ etapa "desenvolvendo o trajeto e selecionando as estratégias" estudaram-se as possibilidades de intervenção, confrontando a análise com o suporte teórico para a ação, ou seja, avaliou-se que ferramentas facilitariam ou contribuiriam para a solução dos problemas identificados.

Em seguida, no passo seguindo e agindo, realizouse a intervenção desenvolvendo as estratégias planejadas para a situação diagnosticada. Foi a partir deste movimento, que a prática se definiu, permitindo ao profissional perceber a sua realidade e a realidade estudada com um novo olhar, construindo um papel de transformação na sociedade.

Finaliza-se com a etapa "acompanhando a trajetória", em que foi realizada uma avaliação dos encontros. Segundo eles, foram boas, "aprendi algumas coisa, o que devo e não devo fazer..." A participação deles foi excelente, já se percebia um vínculo construído naquele grupo. 0 objetivo foi provocá-los a refletir sobre a qualidade de suas vidas. A partir dos encontros realizados, observase que foi plantada uma semente, que algum dia poderá despertar a vontade destes jovens em querer mudar as suas vidas.

A prática consistiu de dez encontros semanais, de aproximadamente duas a três horas, nos quais desenvolvemos várias atividades, como: dinâmicas de grupo, atividades de estudo com letras de músicas, debates, desenvolvimento de trabalhos em grupos, filmes sobre a temática e uma avaliação com os grupos sobre o trabalho realizado.

Utilizou-se como referencial a teoria existencialhumanista, que trabalha essencialmente com relações humanas e fornece subsídios para torná-las mais sadias e fecundas, estimulando as potencialidades do indivíduo. Por meio do tema de ação e crescimento dos adolescentes, sob este referencial, entende-se que a função do indivíduo perante a vida é a realização pessoal. 0 objetivo é fazer 0 indivíduo valorizar a sua existência, buscando na essência aquilo que ele possui de mais íntimo, precioso e individual, durante a sua vivência e experiência. A partir de uma perspectiva saudável do desenvolvimento do indivíduo, Rogers incentiva novas tendências e esperanças do mundo educacional, por meio do conceito de autorrealização, autonomia e criatividade. ${ }^{9}$

\section{Construção do projeto assistencial de sensibilização à prevenção das drogas para a promoção da saúde juvenil}
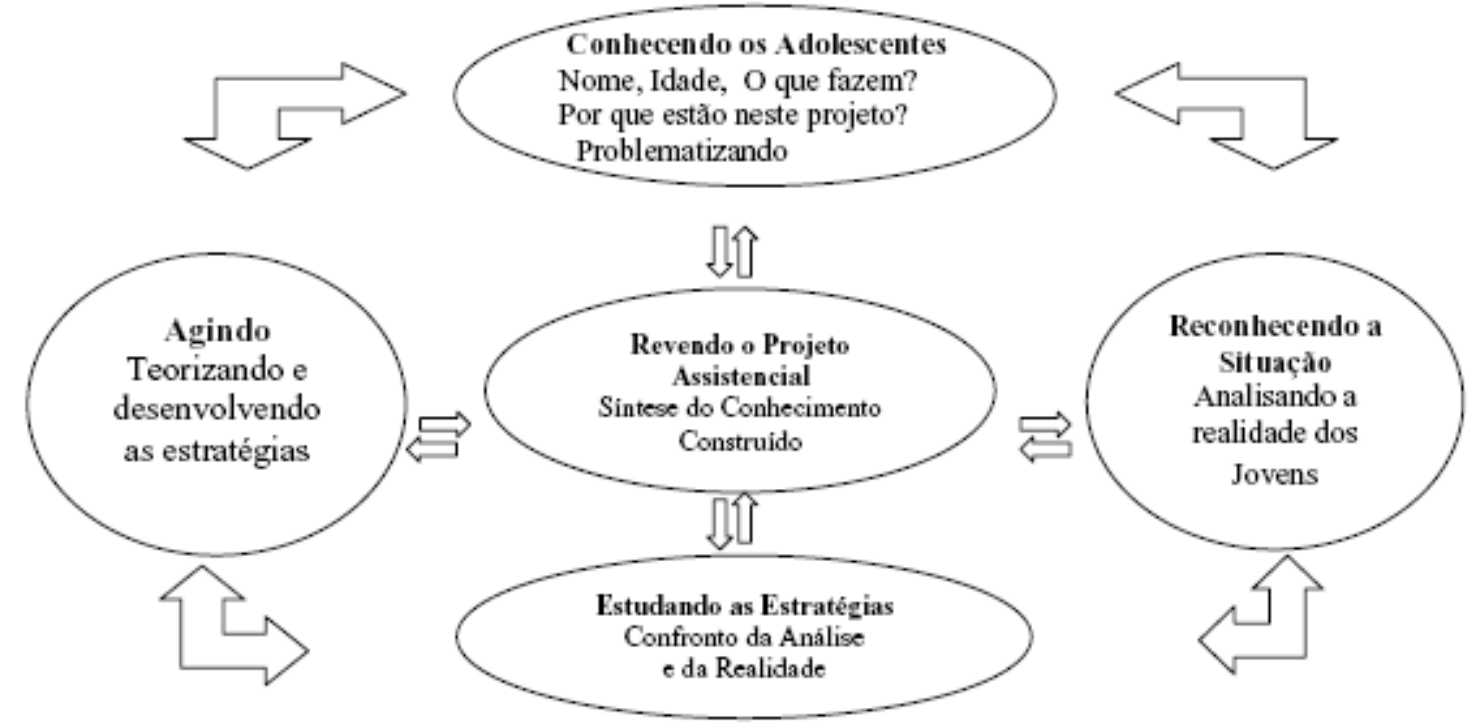

Representação gráfica de Mendes adaptada por Carraro. ${ }^{\text {II }}$ 
Apresentando as Oficinas: autonomia, autorrealização e criatividade

Para desenvolver comportamentos de prevenção ao uso de drogas, não é preciso necessariamente falar de drogas o tempo todo, porque dessa forma pode-se reforçar o seu uso.

Em alguns encontros, as dinâmicas não funcionaram, interrompia-se a dinâmica, se fazia um círculo, conversávamos e discutíamos sobre algumas ideias a respeito da vida. Geralmente, me ouviam, até porque eu não estava ali para dizer o que eles já sabiam, mas para ouvi-los e argumentar sobre algumas ideias que tínhamos a respeito do mundo, estimulá-los para que não desistissem de fazer alguma coisa por si mesmos e responsabilizar-se pela forma como vivem, mas que poderiam lutar para fazer algo diferente. Traziam à discussão posições preconcebidas, que eram confrontadas com fatos que apontavam para a existência de possibilidades de viver de outras formas, fazendo outras escolhas, mesmo em condições adversas. Eles ouviam, prestavam atenção nas discussões, e percebeu-se que, apesar de desgastantes, os encontros foram fundamentais para a criação do vínculo entre os participantes.

A argumentação desenvolvida ao longo das discussões esteve embasada em alguns conceitos associados à educação para a responsabilização do sujeito dentro da sua realidade, que é o preceito fundamental. Para alguns, a droga é uma solução social. Por meio da droga, obtém-se importância e se é desresponsabilizado pela sociedade. Sem a droga, se é nada, um qualquer; ao contrário, com a droga nos sentimos importantes porque todo mundo fala da droga. Isso apenas sublinha a cultura da doença e a ilusão que circula em torno do mito da droga. De uma mãe de família que tenha tido um amor particular, um afeto vicioso, pelo sujeito, se faz transposição a um afeto vicioso da sociedade. Mas o engano é para o dependente. ${ }^{12}$

Percebe-se que hoje, com o avanço da tecnologia e da globalização, a razão leva a uma verdade absoluta que não traduz a realidade dos fatos. Depara-se com várias verdades, válidas para uma ou outra situação, mas nunca universais absolutas. É natural que diante desse quadro o indivíduo sintase inseguro, desordenado e instável. No entanto, mesmo com a pluralidade, muitas vezes contraditória e que gera confrontos, com as transformações e desafios psicológicos, culturais, econômicos, educacionais, sociais e simbólicos, o indivíduo anseia buscar formas de liberdade e de igualdade para o seu bem-estar na sociedade. Tenta-se realizar essa liberdade e igualdade a partir das diferentes instituiç̧ões sociais, sendo que uma delas é a educação. Por isso, é fundamental mostrar o quanto esses preceitos influenciam no conceito educacional da atualidade..$^{13}$ Atualmente, a opinião mais difundida é que, essencialmente, o ser humano não é livre. Não é livre em um sentido cultural. Evidentemente, é um peão do governo. É modelado, pela propaganda de massa, para ser uma criatura com determinadas opiniões e crenças, desejadas ou planejadas com antecedência pelos poderes competentes. É o produto de sua classe-baixa, média ou superior e seus valores, e comportamentos são formados pela classe a que pertence. Portanto, parece cada vez mais claro, a partir do estudo das instituições e influências sociais, que o ser humano é apenas a criatura de sua cultura e suas condições; indiscutivelmente, não é livre. ${ }^{9}$

Na linguagem política, há dois tipos de significados de liberdade: uma é a liberdade negativa, e outra é a liberdade positiva. ${ }^{14} \mathrm{~A}$ liberdade negativa é entendida como ausência de impedimento ou de constrangimento, ou seja, o indivíduo tem a possibilidade de agir sem ser interrompido, ou de não agir sem ser imposto, por terceiros. Logo, essa liberdade se qualifica pela ação impensada do indivíduo, que quer dizer que a ação não é impedida, mas sim realizada. Já a liberdade positiva é qualificada pela vontade, porque depende do próprio querer do indivíduo, ou seja, da sua autodeterminação. Segundo, a linguagem filosófica de Rousseau, essa autodeterminação qualifica uma vontade, não com base em impulsos, mas com base na razão humana, pois o indivíduo é livre para pensar racionalmente, criar e recriar regras, desde que não passe por cima daquelas regras já formuladas. Ou nas palavras de Montesquieu, "a liberdade é o direito de fazer tudo o que as leis permitem". ${ }^{14}$

Visto que a liberdade positiva referenda a visão moderna e está associada à formação do ser autônomo e responsável pelas suas ações, para compreensão adequada da liberdade positiva, é fundamental refletir sobre os termos que envolvem este conceito, a saber: autonomia, autorrealização e criatividade.

A autonomia pode ser compreendida no sentido de dar as leis a si mesmo e obedecê-las, ou seja, é a liberdade do agir e do querer que capacita o indivíduo a determinar sua própria vida, tomando como base os recursos da razão. Representa a capacidade de o indivíduo de determinar a sua vida perante as leis. Assim, é um processo que possibilita que a pessoa aja e aprenda racionalmente, tomando como base 0 equilíbrio da utilização da razão e da emoção. Logo, será adquirida por meio da educação na família e na escola.

Tendo como base este conceito, observa-se o quanto os adolescentes usuários de drogas são aprisionados. Eles colocam a droga como uma forma de liberdade, mas uma liberdade negativa, sem limites, sem regras, agindo impulsivamente, do modo que acham mais conveniente naquele momento, sem considerar as consequências futuras. Se observarmos esse ponto de vista, não é coerente com a realidade destes adolescentes, que não tiveram educação nem na escola e muito menos na família. São representantes de uma vida caótica e desequilibrada.

Há muitos anos, August Aichorn realizou um experimento radical de reeducação de delinquentes. Dentro da instituição, no grupo em que era o chefe, deu-lhes liberdade para que se comportassem como desejassem. Depois de um 
período de caos que, sem dúvida, poucos suportariam, esses adolescentes gradativamente escolheram uma vida social, disciplinada e cooperativa. Aprenderam, por meio da vivência de uma relação de aceitação, que preferiam uma liberdade responsável, e limites autoimpostos, ao caos da desordem e da agressão. $^{14}$

É importante que o jovem perceba que os conhecimentos adquiridos ao longo da vida estão inacabados. 0 professor é um facilitador da formação do jovem, mas quem vai construí-la é o próprio indivíduo. Isso significa que a formação da autonomia envolve a responsabilidade do livre-arbítrio, ou seja, o aprendizado, o conhecimento. Trata-se de uma "ferramenta" que está em constante atualização, e a utilização desta envolve um comprometimento com as consequências, que se firmará à medida que o indivíduo tenha o discernimento de que é a sua ação íntima e pessoal que determina significativamente o rumo de sua própria vida e a sua contribuição no contexto global. "0 aluno forma na escola a representação de um conhecimento em gestação. Isto é, o professor, inicialmente na função de tutor, comunica conteúdos supostamente atualizados, mas despertando ao mesmo tempo essa consciência de que a ciência não parou, logo, despertando o desejo e aptidão para participar de sua criação. Esta é a esperada contribuição da escola para a formação de uma autonomia de cunho epistemológico". ${ }^{15}$

De acordo com a realidade destes adolescentes, eles temem a escola. Alguns argumentam que pararam de estudar devido ao medo de apanhar e serem coagidos a fazer algo que eles não queriam, como traficar a droga dentro da escola.

No entanto, entram em contradição, como em um encontro em que assistimos ao filme Cidade de Deus. 0 filme foi um excelente instrumento de trabalho, porque foi a forma mais fácil de fazê-los ver uma realidade, talvez, próxima da sua. Eles ficaram interessados e destacavam as cenas que mais gostavam, relacionando-as com as suas vidas. Discutiram algumas questões sobre a violência; ao serem questionados quanto às suas preferências por cenas de violência e agressividade, eles respondiam que é porque "é legal e divertido".

Na teoria, observa-se que o educador idealiza formar indivíduos autônomos, críticos, construtivos, criativos, equilibrados entre a razão e emoção. No entanto, observamos o quanto é difícil construir essa ideia na prática, dependendo do tipo de grupo com que se trabalha. Por isso, a importância de desenvolver o senso de humanidade e responsabilidade na família, na escola, enfim na sociedade em geral. Todos devem ter o mesmo princípio lógico na formação do humano, ou seja, jogar no mesmo time. ${ }^{9}$

Quanto à autorrealização, conceitua-se como 0 encontro dos verdadeiros objetivos da vida do indivíduo. É o que o direciona a uma maior coerência e uma boa funcionalidade no decorrer do seu desenvolvimento. Dentro de cada ser humano há um ponto, um núcleo positivo base, onde o ser estabelece o próprio sentido apriórico que universaliza o homem para a autorrealização. Cada indivíduo, em qualquer momento do próprio processo interativo, estabelece uma convergência de vantagem que é única para atingir a própria autorrealização. Conseguir conscientizar e se coordenar em ação específica no sentido único de cada situação é crescimento segundo o sentido fundamental apriórico, é realização do fim personológico. ${ }^{12}$

No aspecto psicológico, todo indivíduo exibe uma motivação que o conduz à realização de suas potencialidades. Se houver boas condições que permitam o crescimento, essa tendência direcional positiva leva à ação construtiva; ou seja, tudo faz parte da identificação do indivíduo com a ação, com o fenômeno que, codificado pelo organismo por meio de uma emoção, deve objetivar o seu crescimento e seu potencial em criar. $^{9}$

A autorrealização engloba as satisfações biológicas, 0 reconhecimento das potencialidades para o indivíduo sobreviver física e socialmente, o desenvolvimento da autonomia, da independência, e um profundo sentimento de autodeterminação. Ou seja, é considerada um impulso dominante, pelo qual o ser humano busca incessantemente e de maneira original desenvolver suas potencialidades na integralidade com os meios que estão ao seu alcance. ${ }^{16}$

Verifica-se o fundamento da tendência autorrealizadora também no campo da biologia. Em experimento realizado com ouriços do mar, em que foram separadas as duas células que se formam após a primeira divisão do ovo fertilizado, se tivessem se desenvolvido normalmente, pela lógica, uma delas teria se transformado em uma parte do ouriço, sendo que ambas seriam necessárias à formação da criatura inteira. Portanto, parece evidente que, quando as duas células são separadas e conseguem crescer, cada uma delas responderá apenas pela parte do ouriço que lhe cabe. Mas esta suposição desconsidera a tendência direcional e autorrealizadora, característica de todo crescimento orgânico. Logo, o resultado encontrado foi que cada célula, conservada viva, se transforma em uma larva de ouriço do mar, inteira - um pouco menor do que o comum, mas normal e completa. ${ }^{16}$

Percebe-se que a autorrealização é uma característica inerente a qualquer ser vivo. Porém, assim como a autonomia, identifica-se no ser humano como uma característica que para além da biologia, exige o uso da razão e torna-se mais complexa no meio social.

De acordo com o exemplo do ouriço, percebe-se que 0 funcionamento do indivíduo, com relação ao escopo de autorrealização, corrobora um processo natural. Aliás, o ser humano é e faz parte da natureza, por isso a autorrealização é o principal objetivo da vida do indivíduo e um dos meios para alcançá-la é a própria criatividade. "Cada organismo tem um impulso primário, que é governado pela tendência a atualizar tanto quanto possível sua própria natureza, para conviver mais adequadamente com o mundo. É uma tendência criativa de o indivíduo se desenvolver em sua totalidade" . 16:35 
A educação que busca a formação de um indivíduo construtivo demanda concomitantemente a atenção a aspectos de autonomia e criatividade, uma vez que o ser construtivo é aquele que é 0 agente, e precisa estar apto para tal, consciente de seus próprios limites e organizado criativamente para agir com funcionalidade.

A criatividade é uma ação inédita de um produto novo proporcionado pela própria natureza do indivíduo, ou que provém de materiais, acontecimentos, pessoas ou circunstâncias da sua vida. Percebe-se que a causa principal da criatividade é a tendência do indivíduo a se realizar, de vir a exercer as suas potencialidades.

É um termo que denomina o atributo de conduzir para além do que é comum, frequente, natural. Não se pode reduzir este grande termo à exclusiva função da criança que dá seus primeiros passos, faz os primeiros rabiscos, coloca cores ou faz ações conforme as indicações de seu professor, e tudo isso é ainda processo de iniciação antropológica. A criatividade é individual, é um potencial da natureza que o indivíduo deve exercitar criticamente por meio da escola, para depois operar no íntimo da própria inteligência aquela síntese única que produz uma função autogenética de novidade..$^{12}$

Apesar da suposta importância desse conceito na formação do ser construtivo e autônomo, observa-se que esses adolescentes, por viverem de uma forma de autonomia precária, enfrentam limites em sua autorrealização, mas são extremamente criativos em algumas ações que eles julgam positivas. É assim que encontram formas de conseguirem algo que desejam muito, mesmo que não seja funcional para suas vidas.

\section{CONSIDERAÇÕES FINAIS}

Na teoria humanista, obtiveram-se experiências com indivíduos diversificados, enfocando a questão da criatividade e da responsabilidade como facilitadores da liberdade, predominante na abordagem educacional proposta pela Abordagem Centrada na Pessoa. Nesta prática educativa, não se fala da técnica, e sim da maneira como desenvolvê-la centrada na pessoa. Por meio da liberdade de criação e de formas de educar o adulto, o indivíduo pode ser responsável, criativo e ao mesmo tempo saber viver em harmonia com a sociedade, possibilitando um bom desempenho profissional no futuro. ${ }^{9}$

De acordo com um estudo realizado por Rogers, alguns tipos de grupos acentuam valores que se manifestam na espontaneidade, no viver o presente, na intimidade da relação, na expressão dos sentimentos, na solidariedade, entre outros. Percebem-se esses valores estudados por alguns autores importantes, como Maslow, Rogers, May, e pela corrente conhecida por Psicologia Humanística, nos adolescentes que participaram desta experiência.
Todos estes conceitos são fundamentais para elucidar qualquer reflexão sobre a educação hoje, pois o principal objetivo dos agentes da educação é facilitar o processo de aprendizagem do aluno, por meio da soma do conhecimento técnico com o crescimento pessoal, promovendo uma aprendizagem funcional: "Situação educacional trata-se de um conjunto de valores, difíceis de atingir, que dão ênfase à dignidade do indivíduo, à importância da escolha pessoal, à significação da responsabilidade, à alegria da criatividade. É uma filosofia, construída sobre os fundamentos do modo de vida democrático, a dar poderes a todo indivíduo". 9:102

Neste sentido, observou-se, durante esta prática, a importância do modelo de cuidado utilizado, pois facilitou o destaque da fase da inclusão dos adolescentes, que se deu de uma forma lenta e gradativa. A necessidade de sentir-se aceito, valorizado e considerado pelas pessoas que compõem o grupo não acontece logo no primeiro encontro, o coordenador deve estar atendo e oferecer condições para que cada pessoa conheça os demais e se deixe conhecer, por meio de controle e afeição, estabelecendo características particulares para cada pessoa e que encontre o seu lugar no grupo.

A relação interpessoal acontece muitas vezes simultaneamente, e ressalva-se que cada grupo possui uma dinâmica particular que merece atenção e estudo especial para aquele que se propõe a coordenar seu desenvolvimento.

Foi um desafio a realização desta prática, em função de ter sido desenvolvida com adolescentes em liberdade assistida, mas, por outro lado, foi a oportunidade de aliar os conhecimentos teóricos do curso de especialização com a prática em um contexto nem sempre enfrentado pelos profissionais de saúde.

0 senso da responsabilidade cresce proporcionalmente à consciência de liberdade. Quanto mais livre o indivíduo for, mais responsável se sentirá pela manutenção de sua liberdade, e isso pode estimular a criatividade na realização de suas ações, observando as leis que podem manter sua liberdade e autonomia. Ou seja, a liberdade pode gerar a criatividade, mas se não for obtida de uma forma educativa, responsável, atentando à autonomia defendida pela modernidade, não permitirá que o indivíduo compreenda a sua realidade, fazendo com que aja de forma incongruente com a sua própria vida e infrinja regras sociais, impossibilitando sua autorrealização. "Responsabilidade deriva do latim (res = o que, que coisas ponderar), equilibrar, pesar a multiplicidade de atitudes. Tanto na faculdade de responder, como na de confrontar, implica um primeiro elemento: 0 eu. Elemento justificável em uma relação triádica: eu, tu e a res. Eu estou aqui; os eventos acontecem, introduzem-se em mim. Eu devo reagir, evitálos significaria ser dominado por eles. A responsabilidade é, simultaneamente, responder confrontando tanto um quanto outro". 12:17 


\section{REFERÊNCIAS}

1. Lei $n^{0} 8069$, de 13 de julho de 1990. Dispõe sobre o Estatuto da Criança e do Adolescente e dá outras providências. Diário Oficial da República Federativa do Brasil, Brasília (DF), 16 jul 1986.

2. Zagury T. Encurtando a adolescência. $9^{\mathrm{a}}$ ed. Rio de Janeiro(RJ): Record; 2003.

3 .Organização das Nações Unidas- OMS. Escritório das Nações Unidas contra drogas e crime. Relatório Mundial sobre Drogas- 2008. Brasília (DF): UNODC Brasil e Cone Sul; 2008.

4.Presidência da República (BR). Secretaria Nacional Antidrogas. Política Nacional sobre Drogas. Brasília (DF); 2005.

5 Carlini EA. Primeiro levantamento domiciliar sobre o uso de drogas psicotrópicas no Brasil. São Paulo (SP): SENAD; 2002.

6.Organización de los Estados Americanos-0MS. Comisión Interamericana para el Control del Abuso de Drogas. Lineamientos hemisféricos de la CICAD en prevención escolar. Washigton(USA); 2005.

7. Martini JG. Representações de professores associadas ao uso de drogas na escola básica. [monografia]. Ribeirão Preto (SP): USP; 2006.

8. Galduróz J, Carlini EA, Noto A, Fonseca A. Levantamento nacional sobre o consumo de drogas psicotrópicas entre estudantes do ensino fundamental e médio da rede pública de ensino nas 27 capitais brasileiras. São Paulo (SP): SENAD; 2004.

9. Rogers C. Sobre o poder pessoal. São Paulo (SP): Martins Fontes; 1977.

10 Lüdke M, André M. Pesquisa em educação: abordagens qualitativas. São Paulo (SP): EPU; 1986.

11. Carraro TE. Resgatando Florence Nightingale: a trajetória da enfermagem junto ao ser humano e sua família na prevenção de infecções. [dissertação de mestrado]. Florianópolis: UFSC; 1994.

12. Meneghetti A. Pedagogia ontopsicológica. Recanto Maestro (RS): Ontopsicologica Editrice; 2005.

13. Bauman Z. Globalização: as conseqüências humanas. Rio de Janeiro (RJ):Zahar; 1999.

14. Bobbio N. Igualdade e liberdade. Rio de Janeiro (RJ): Ediouro; 1996.

15. Tavares MC. Gestão estratégica: do planejamento à gestão estratégica. São Paulo (SP): Atlas; 2000.

16. Menestrina TC, Menestrina E. Auto-realização e qualidade docente. Porto Alegre (RS): Ed Est; 1996. 